\title{
Treatment strategies to reduce radiotherapy late effects in children
}

\author{
Arnold C. Paulino
}

Received: 16 October 2012 / Accepted: 22 October 2012 / Published online: 6 November 2012

(C) Springer-Verlag Berlin Heidelberg 2012

\begin{abstract}
Late effects of treatment are an important cause of morbidity and mortality in childhood cancer survivors. The use of radiotherapy has been implicated as a risk factor for the development of many late complications. Several strategies have been employed in pediatric oncology to minimize the late effects of radiotherapy. These have included (1) omitting or delaying radiotherapy until the child is older, (2) decreasing radiotherapy doses and volumes by incorporating chemotherapy in the treatment regimen, (3) alteration of radiotherapy fractionation, (4) use of novel techniques to spare or minimize radiation dose to surrounding normal tissues, and (5) elimination of radiotherapy in favorable subsets of patients. In infants with brain tumors, delaying radiotherapy and giving chemotherapy until the child is 3 years old was a popular approach three to four decades ago with limited success with respect to tumor control. With the advent of modern radiotherapy technology, younger patients are now able to be treated with conformal techniques and reasonable neurotoxicity. Using chemotherapy to reduce doses of radiation therapy has been employed in standard-risk medulloblastoma, intracranial germinoma, Hodgkin lymphoma, and Wilms' tumor. Likewise, the use of chemotherapy to reduce radiotherapy volumes has been employed in intracranial germinoma, Hodgkin lymphoma, and neuroblastoma and for the boost portion of treatments
\end{abstract}

\author{
A. C. Paulino $(\bowtie)$ \\ Department of Radiation Oncology, The Methodist Hospital, \\ 6565 Fannin St., DB1-077, \\ Houston, TX 77030, USA \\ e-mail: apaulino@tmhs.org \\ A. C. Paulino \\ Weil-Cornell Medical College, \\ Houston, USA \\ A. C. Paulino \\ Department of Pediatrics, \\ Texas Children's Hospital and Baylor College of Medicine, \\ Houston, USA
}

for rhabdomyosarcoma and Ewing sarcoma. There are a few phase III trials comparing conventional and hyperfractionated radiotherapy, but none of them have shown superiority of one over the other in terms of tumor control and late effects. Current protocols are testing the omission of radiotherapy in the most favorable subset of patients with Hodgkin lymphoma and Wilms' tumor. Intensity-modulated radiation therapy is currently used in many children in developed nations. Proton therapy is available in a few centers; clinical results of treatment are accumulating regarding the effectiveness and longterm toxicity of this radiation modality.

Keywords Pediatric cancers $\cdot$ Late effects $\cdot$ Radiotherapy

\section{Introduction}

In the USA, cancer is the second leading cause of death in children. Over the past 30 to 40 years, the survival of children with cancer has improved markedly (Table 1). The 5-year overall survival (OS) rate was $58 \%$ from 1975 to 1977 ; this contrasts to the 5-year OS rate of $83 \%$ from 2001 to 2007 [1]. Because more children are surviving from cancer, attention to the late effects of treatment has become more important. Recent studies have shown that about $25 \%$ of deaths in 5-year survivors of childhood cancer can be attributed to treatment [2].

Surgery, chemotherapy and radiotherapy (RT) have all been associated with different late toxicities. RT has been shown to be a major contributor in the development of late toxicity from treatment $[2,3]$. While RT can cause inflammatory and fibrotic reactions in both children and adults, some late complications are seen only in children because RT can impair the growth and development of normal organs [4]. Furthermore, younger patients are more susceptible to development of secondary cancers [3]. Over the past years, there has been emphasis on minimizing the use of RT in many 
Table 1 The 5-year overall survival (in percent) of patients (ages 0 to 14 years) with childhood cancer over time based on the Surveillance Epidemiology and End Results review [1]

\begin{tabular}{lcccc}
\hline Type of cancer & $1975-1977$ & $1984-1986$ & $1993-1995$ & 2002-2008 \\
\hline Bone and joint & 49.9 & 57.3 & 74.1 & 78.8 \\
Brain and central nervous system & 56.9 & 61.8 & 70.6 & 74.5 \\
Hodgkin lymphoma & 80.7 & 90.9 & 94.6 & 97.4 \\
Leukemia & 50.3 & 63.9 & 76.0 & 86.6 \\
Neuroblastoma & 52.5 & 52.3 & 67.3 & 73.5 \\
Non-Hodgkin lymphoma & 43.2 & 70.3 & 80.7 & 85.3 \\
Soft tissue & 61.0 & 72.9 & 76.7 & 82.0 \\
Wilms' tumor & 73.1 & 90.7 & 91.7 & 90.1 \\
All types & 58.1 & 68.2 & 77.4 & 82.8 \\
\hline
\end{tabular}

pediatric tumors. Several strategies have been employed in pediatric oncology to minimize the late effects of RT. These have included (1) omitting or delaying RT until the child is older, (2) decreasing RT doses and volumes by incorporating chemotherapy in the treatment regimen, (3) alteration of RT fractionation, (4) use of novel techniques to spare or minimize RT dose to surrounding normal tissues, (5) elimination of RT in favorable subsets of patients, and (6) reduction of RT volume through analysis of patterns of failure. This review outlines the different strategies that have been used including the published results of these treatments.

\section{Omitting or delaying RT in the very young}

Infants are the most susceptible to RT late complications such as cognitive deficits and growth problems. During the first few years of life, the brain, muscle, and bones are in a phase of rapid growth which slows down at around 7 years. A second peak of growth occurs in the musculoskeletal system at puberty. Consequently, some oncologists have advocated omitting or delaying RT in the very young until the child is older.

A popular approach three to four decades ago was delaying RT in infants with malignant brain tumors. Children less than 3 years of age underwent a maximal safe resection followed by 12 to 24 months of chemotherapy until the child was 3 years of age or until progression occurs. The results of this approach have been inferior compared with studies with older patients who are able to undergo craniospinal or cranial RT. The Pediatric Oncology Group infant study showed a 1- and 2year progression-free survival of 42 and $34 \%$ in medulloblastoma and 58 and $42 \%$ in ependymoma using two courses of vincristine and cyclophosphamide alternating with one course of etoposide and cisplatin [5]. The French Society of Pediatric Oncology (SFOP) has reported a 4-year progression-free survival of $22 \%$ in ependymoma after resection and postoperative chemotherapy [6]. In an analysis of the Surveillance Epidemiology and End Results database, children $<3$ years of age with ependymoma who receive immediate postoperative RT have a better 3-year OS compared with those not receiving postoperative RT ( 81 vs. $56 \%, p=0.005$ ) [7]. A report from St. Jude Children's Research Hospital showed a 3-year progressionfree survival of $74.7 \%$ in 88 children with a median age of 2.9 years after postoperative RT for ependymoma. Neurocognitive testing revealed stable findings, with more than half of the children tested at or beyond 2 years [8]. A strategy of omitting RT in medulloblastoma patients was performed in Germany using three cycles of cyclophosphamide, vincristine, methotrexate, carboplatin, and etoposide in addition to intraventricular methotrexate. The 5-year progression-free and OS rates were 82 and $93 \%$ for the 17 patients who had complete resection, 50 and $56 \%$ for those with residual tumor in the postoperative bed and $33 \%$ and $38 \%$ for those with macroscopic metastasis. A surprising finding in the study is the better outcome of patients with desmoplastic compared with classic medulloblastoma [9].

Infants $<1$ year old with rhabdomyosarcoma have a worse survival outcome compared with older patients primarily because of a higher local failure rate secondary to omission of RT. A report from the Italian Cooperative Group showed a local failure rate of 54 and $28 \%$ in those who did not have and those who had RT when there was an indication for treatment [10]. Investigators from Memorial Sloan-Kettering Cancer Center have shown a 2-year local control of $84 \%$ with RT in children $<3$ years of age with rhabdomyosarcoma. Mild functional deficits were seen using primarily a conformal RT approach; however, follow-up is short to determine the true extent of late toxicity [11].

\section{Use of chemotherapy to lower RT dose and volume}

In certain brain tumors, chemotherapy has been used to decrease RT volume and dose. In children with standard-risk medulloblastoma, 23.4 Gy craniospinal RT followed by posterior fossa boost and adjuvant chemotherapy seem to have an equivalent and maybe better survival compared with those who have received 36 Gy craniospinal RT followed by posterior fossa boost without adjuvant chemotherapy [12, 13]. 
There is also evidence that the tumor bed with a margin can be safely treated to a higher dose instead of the entire posterior fossa when chemotherapy is used [14]. Neurocognitive studies have shown that patients receiving 23.4 Gy craniospinal RT had fewer declines in mean intelligence quotient (IQ) scores compared with those receiving 36 Gy craniospinal RT in both younger ( $<7$ years) and older ( $\geq 7$ years) patients [15]. Another intracranial tumor where chemotherapy may impact on RT fields and doses is germinoma. For decades, the standard treatment for intracranial germinoma has been craniospinal RT. Some studies have shown that whole brain and whole ventricular RT fields followed by a boost may suffice in patients with M0 or non-metastatic disease. More recently, neoadjuvant chemotherapy has been used to shrink the tumor and tailor RT fields and doses [16]. A Children's Oncology Group (COG) study randomizing patients to RT alone versus neoadjuvant chemotherapy followed by RT recently closed because of poor accrual. In patients with a complete response (CR) after neoadjuvant chemotherapy, RT is given to the primary site only and given $30 \mathrm{~Gy}$. Patients who do not obtain a CR or who are randomized to RT alone receive whole ventricular RT to $24 \mathrm{~Gy}$ followed by a boost to the primary site for a total dose of 45 Gy. The SFOP published their results using four cycles of chemotherapy followed by 40 Gy RT to the primary site alone, regardless of chemotherapy response; 10 of 60 patients relapsed. Eight of the ten relapses were periventricular, suggesting that whole ventricular region should have been treated [17].

In stage III favorable histology Wilms' tumor, the addition of doxorubicin to actinomycin-D and vincristine has allowed a dose reduction from 20 to 10 Gy flank or abdominal RT [18]. A study from the University of Iowa has shown lower proportion of patients with scoliosis by using less RT dose [19]. In Hodgkin lymphoma, children have traditionally been treated with subtotal nodal RT alone to doses of 40 to 44 Gy with subsequent musculoskeletal growth abnormalities [20]. In the past three decades, this approach has been challenged in children, where the current management is to deliver multiagent chemotherapy followed by involved-field RT to doses of 15 to 25.5 Gy with similar survival outcomes $[21,22]$. The reduction of RT fields and lowering of dose has reduced the amount of breast tissue receiving radiation. Likewise, retardation of bone growth which seems to be more prominent above 25 Gy should also be reduced with this approach. Studies from the Netherlands Cancer Institute and Stanford University have conflicting results regarding the reduction of secondary breast cancer following involved field RT [23, 24]. A study from St. Jude Children's Research Hospital has shown that even with a dose of $15 \mathrm{~Gy}$, growth of the clavicle can still be impaired after asymmetric mantle RT, more prominent in younger children [25].

\section{Alteration of RT fractionation}

Hyperfractionation delivers a lower dose per fraction given more than once a day. Because the late effects of RT are directly related to the fraction size, lowering the dose per fraction, in theory, should reduce late complications. Retrospective analysis of musculoskeletal complications after hyperfractionated RT for Ewing sarcoma at the University of Florida has shown less fracture, loss of range of motion, loss of muscle circumference and atrophy in patients receiving hyperfractionated compared with conventional RT [26]. A review of patients treated with hyperfractionated RT for medulloblastoma at the New York University has shown a lower incidence of hypothyroidism in those receiving hyperfractionated compared with conventional RT [27].

There are at least five randomized trials in pediatric radiation oncology comparing conventional fractionation to hyperfractionated RT (Table 2). Some have used a hyperfractionated regimen to increase dose and local tumor control while keeping the same late effects as conventional RT [28-31]. In one of the protocols, RT was a hyperfractionated split-course regimen [30]. Others have given the same dose in a hyperfractionated manner with the aim of reducing long-term toxicity [32]. In all of these trials, there has been no documented improvement as far as local control or late toxicity with hyperfractionated RT.

\section{Use of novel RT technology}

In the last two decades, many advances have occurred in RT treatment delivery. Three-dimensional conformal radiotherapy (3D-CRT) has been shown to improve target volume coverage as well as sparing of surrounding, normal tissues from high dose-RT when compared with conventional RT [33, 34].

Intensity-modulated radiation therapy (IMRT) has also been used in the treatment of children with brain, head and neck and soft tissue tumors. The local control rates with IMRT have been shown to be equivalent if not better than conventional RT in children (Table 3) [14, 35-43]. A comparison of 3-DCRT and IMRT in pediatric nasopharyngeal carcinoma showed no difference in the 2-year locoregional control but less grade 3 acute toxicities of the skin, mucous membrane and pharynx with IMRT [37]. In COG D9803, the 5-year locoregional failure rates were $18 \%$ for $3 \mathrm{D}-\mathrm{CRT}$ and $15 \%$ for IMRT. While the locoregional control rates were not statistically different, target dose coverage was better for IMRT [42]. Regarding late toxicity, the main complication that IMRT might have an advantage compared with more conventional techniques is ototoxicity in children receiving RT and cisplatin for medulloblastoma [35, 44, 45]. The initial paper from The Methodist Hospital of 15 patients with a median follow-up of 18 months demonstrated a reduction 
Table 2 Randomized trials in childhood cancer comparing conventional to altered fractionation radiation therapy

\begin{tabular}{|c|c|c|c|}
\hline Tumor type/study (reference) & Conventional fractionation dose & Altered fractionation dose & Outcome \\
\hline $\begin{array}{l}\text { Group III rhabdomyosarcoma/ } \\
\text { Intergroup Rhabdomyosarcoma } \\
\text { Study-IV [28] }\end{array}$ & $\begin{array}{l}50.4 \text { Gy in } 28 \text { fractions over } \\
5.5 \text { weeks ( } 1.8 \text { Gy once a day) }\end{array}$ & $\begin{array}{l}59.4 \mathrm{~Gy} \text { in } 54 \text { fractions over } \\
5.5 \text { weeks ( } 1.1 \text { Gy twice daily) }\end{array}$ & $\begin{array}{l}\text { No difference in local control or } \\
\text { late toxicity. More acute toxicity in } \\
\text { head and neck subset of } \\
\text { patients treated with } \\
\text { hyperfractionated RT }\end{array}$ \\
\hline $\begin{array}{l}\text { Diffuse intrinsic pontine glioma/ } \\
\text { Pediatric Oncology } \\
\text { Group-9239 [29] }\end{array}$ & $\begin{array}{l}54 \text { Gy in } 30 \text { fractions over } \\
6 \text { weeks ( } 1.8 \text { Gy once a day) }\end{array}$ & $\begin{array}{l}70.2 \text { Gy in } 60 \text { fractions over } \\
6 \text { weeks ( } 1.17 \text { Gy twice daily) }\end{array}$ & No difference in survival or toxicity \\
\hline $\begin{array}{l}\text { Localized Ewing sarcoma/ } \\
\text { Cooperative Ewing Sarcoma } \\
\text { Study } 86[30]\end{array}$ & $\begin{array}{l}45 \text { Gy to extended field volume } \\
\text { and } 60 \text { Gy to boost volume over } \\
6 \text { to } 6.5 \text { weeks ( } 1.8 \text { to } 2 \text { Gy once a day) }\end{array}$ & $\begin{array}{l}44.8 \text { Gy to extended field and } \\
60.8 \text { Gy to boost volume (1.6 Gy } \\
\text { twice daily up to } 22.4 \text { Gy then break, } \\
\text { RT given in } 3 \text {-week intervals until } \\
\text { dose of } 60.8 \text { Gy) }\end{array}$ & $\begin{array}{l}\text { No difference in local control, } \\
\text { survival, or toxicity }\end{array}$ \\
\hline $\begin{array}{l}\text { Standard-risk medulloblastoma/ } \\
\text { German brain tumor trial, International } \\
\text { Society of Pediatric Oncology primitive } \\
\text { neuroectodermal tumor (HIT-SIOP } \\
\text { PNET)-4 [31] }\end{array}$ & $\begin{array}{l}23.4 \text { Gy to craniospinal axis and } \\
54 \text { Gy to whole posterior fossa } \\
\text { over } 6 \text { weeks ( } 1.8 \text { Gy once daily) }\end{array}$ & $\begin{array}{l}36 \text { Gy to craniospinal axis, } 60 \mathrm{~Gy} \\
\text { to whole posterior fossa and } 68 \mathrm{~Gy} \\
\text { to tumor bed over } 7 \text { weeks } \\
\text { (1 Gy twice daily) }\end{array}$ & $\begin{array}{l}\text { No difference in event-free and } \\
\text { overall survival. No difference in } \\
\text { severe hearing loss }\end{array}$ \\
\hline $\begin{array}{l}\text { High-risk acute lymphoblastic } \\
\text { leukemia/Dana Farber Cancer Institute } \\
\text { Acute Lymphoblastic Leukemia } \\
\text { Consortium } 87-01 \text { and 91-01, [32] }\end{array}$ & $\begin{array}{l}18 \text { Gy in } 10 \text { fractions over } \\
2 \text { weeks ( } 1.8 \text { Gy once daily) }\end{array}$ & $\begin{array}{l}18 \text { Gy in } 20 \text { fractions over } \\
2 \text { weeks ( } 0.9 \text { Gy twice daily) }\end{array}$ & $\begin{array}{l}\text { No difference in central nervous } \\
\text { system relapse or cognitive } \\
\text { function }\end{array}$ \\
\hline
\end{tabular}

from 64 to $13 \%$ grades 3 to 4 hearing loss with lowering of RT dose to the cochlea [44]. A more recent analysis with 44 children and a median audiogram follow-up of 41 months showed $25 \%$ grades 3 to 4 hearing loss [45]. Another report from Memorial Sloan-Kettering Cancer Center showed a $6 \%$ grade 3 hearing loss with IMRT at a median audiogram follow-up of 19 months [35]. While increased conformality of the high-dose region to the target is the main advantage of IMRT, there have been several potential disadvantages with the use of this technique [46]. There is increased dose to nontarget tissues secondary to increased low-dose radiation to surrounding critical structures otherwise not delivered with conventional RT from complex beam arrangements as well as increased low-dose radiation to the rest of the body secondary to increased monitor units to deliver desired dose to the target and leakage radiation. This technique, like many of the newer techniques of treatment delivery, requires prolonged treatment planning and delivery time and in some cases, prolonged anesthesia time in the very young.

More recently, the use of proton therapy has gained wide acceptance in the pediatric oncology community. Because of the physical characteristics of the proton beam, there is a theoretical advantage for its use because of the reduction of integral dose to normal tissues when compared with photons. The ability of protons to spare normal tissues beyond a specified depth results in lower or no dose to surrounding organs. Since there are only a few centers in North America, Europe, and Asia using this type of treatment, information regarding clinical outcome is limited and still accumulating. The available literature suggests that local control with proton therapy is comparable to results obtained with IMRT and 3D-CRT; however, the number of patients treated is small, and follow-up is short (Table 4) [47-56]. Whether decreased late toxicity can be achieved by using protons

Table 3 Local control outcome in children with brain, head and neck, and soft tissue tumors treated with intensity-modulated radiation therapy

\begin{tabular}{|c|c|c|c|c|c|}
\hline First author & Institution & Reference & Tumor type & Number of patients & Local control rate \\
\hline Paulino & The Methodist Hospital & [14] & Medulloblastoma & 50 & $90.5 \%$ (5 years $)$ \\
\hline Polkinghorn & Memorial Sloan-Kettering & {$[35]$} & Medulloblastoma & 33 & $84.8 \%$ (median follow-up, 63 months) \\
\hline Schroeder & The Methodist Hospital & [36] & Ependymoma & 22 & $68 \%$ (3 years) \\
\hline Laskar & Tata Memorial Hospital & {$[37]$} & Nasopharyngeal carcinoma & 19 & $76.5 \%$ (locoregional, 2 years) \\
\hline Wolden & Memorial Sloan-Kettering & {$[38]$} & Head and neck rhabdomyosarcoma & 28 & $90 \%$ (3 years) \\
\hline McDonald & Emory Clinic & {$[39]$} & Head and neck rhabdomyosarcoma & 20 & $100 \%$ (3 years $)$ \\
\hline Curtis & The Methodist Hospital & [40] & Head and neck rhabdomyosarcoma & 19 & $92.9 \%$ (4 years) \\
\hline Yang & Memorial Sloan-Kettering & {$[41]$} & Rhabdomyosarcoma & 41 & $90 \%$ (median follow-up, 22 months) \\
\hline Lin & $\begin{array}{l}\text { Children's Oncology Group } \\
\text { (COG) D9803 }\end{array}$ & {$[42]$} & Rhabdomyosarcoma & 87 & $85 \%$ (locoregional, 5 years) \\
\hline Pinnix & MD Anderson Cancer Center & [43] & Desmoplastic small round cell tumor & 8 & $\begin{array}{l}37 \% \text { (locoregional-median follow-up, } \\
15.2 \text { months) }\end{array}$ \\
\hline
\end{tabular}


remains to be seen. A recent prospective study of healthrelated quality of life for children with brains tumors treated with protons showed that at 3-year follow-up, patients treated with protons had very close quality-of-life scores compared with healthy children and better than children with chronic illness [57]. A review of 19 children treated with proton therapy for medulloblastoma showed grades 3 and 4 ototoxicity in $5 \%$ at 1 year follow-up [58]. In another study of brain tumor patients, $47 \%$ receiving protons alone and $33 \%$ of children receiving protons in combination with photons developed endocrine dysfunction [59].

\section{Elimination of RT in favorable subset of patients}

In children with favorable outcomes, one of the strategies has been to determine whether RT can be eliminated in the treatment regimen. In children with stage II favorable histology Wilms' tumor, the National Wilms Tumor Study-3 randomized patients to $20 \mathrm{~Gy}$ RT vs. no RT. In addition, there was a second randomization to vincristine and dactinomycin with or without doxorubicin. Patients who received vincristine and dactinomycin without RT after nephrectomy did very well, eliminating the need for abdominal or flank RT in this favorable subset of patients [18]. Currently in COG AREN0533, the value of whole lung RT in favorable histology Wilms' tumor is being studied. In children with lung metastasis who achieve a pulmonary CR after 6 weeks of vincristine, dactinomycin, and doxorubicin, whole lung irradiation is omitted if the only site of metastasis is the lung and there is no loss of heterozygozity at $1 \mathrm{p}$ and $16 \mathrm{q}$.

In Hodgkin lymphoma, the elimination of involved-field radiotherapy (IFRT) is associated with a slightly worse eventfree survival (EFS) but no difference in OS because of effective salvage therapy. Trials have looked at tailoring treatment based on response to initial chemotherapy (response-adapted therapy). The Children's Cancer Group 5942 study showed a 10-year EFS and OS of 91.2 and $97.1 \%$ for those receiving IFRT and 82.9 and $95.9 \%$ for those not receiving IFRT after an initial CR to chemotherapy. For EFS and OS comparisons, $p=0.004$ and 0.5 , respectively [60]. The German study GPOH-95 also showed a worse EFS in children not receiving IFRT in the intermediate (stage IIEA, IIB, and IIIA) and highrisk groups (stage IIEB, IIIEA, IIIB, and IV) without a difference in OS when compared with those who received IFRT [61]. Current COG protocols (AHOD0431 and AHOD03P1) are examining which patients can RT be safely omitted.

Another group of patients with a favorable outcome are those with intracranial germ cell tumors. An international cooperative trial delivered four cycles of carboplatin, etoposide, and bleomycin to patients with intracranial germ cell tumors [62]. Those who had a CR received an additional 2 cycles of the same agents while those who didn't had intensification with cyclophosphamide. None of the patients had RT as initial part of therapy. A total of $78 \%$ of patients had a CR without irradiation. With a median follow-up of 31 months, $39 \%$ were alive without relapse or progression of disease. Salvage therapy was successful in $93 \%$ of patients who relapsed or progressed.

In children with orbital rhabdomyosarcoma, the standard approach by the Intergroup Rhabdomyosarcoma Study is to deliver RT for group III disease. In Europe, RT is sometimes omitted because of late toxicity in these young patients. A previous report revealed that only $37 \%$ of patients received RT as primary local treatment in SIOP. The 10-year EFS rates for patients receiving RT and no RT were $82 \%$ and $53 \%(p<$ $0.001)$. The 10 -year OS rates were not statistically different ( $88 \%$ and $85 \%$ respectively) [63]. Orbital hypoplasia and cataracts were more common in those who had RT.

While in Hodgkin lymphoma, intracranial germ cell tumor and orbital rhabdomyosarcoma, OS is not different with omission of RT, local failure is higher as well as use of salvage therapy. These issues need to be taken into account in treatment decision making. On one hand, late toxicity is higher in children receiving RT. On the other hand, some patients will never get RT and will have less late effects but the remaining will need salvage therapy (more chemotherapy and use of RT) which would likely have more late toxicity than RT alone.

Table 4 Local control outcome in children with brain and extracranial solid tumors treated with protons

\begin{tabular}{|c|c|c|c|c|c|}
\hline First author & Institution & Reference & Tumor type & Number of patients & Local control rate \\
\hline MacDonald & Massachusetts General Hospital & {$[47]$} & Ependymoma & 17 & $86 \%$ (median follow-up, 26 months) \\
\hline Amsbaugh & MD Anderson Cancer Center & {$[48]$} & Ependymoma (spinal) & 8 & $100 \%$ (median follow-up, 26 months) \\
\hline MacDonald & Massachusetts General Hospital & [49] & Intracranial germ cell tumors & 22 & $100 \%$ (median follow-up, 28 months) \\
\hline Luu & Loma Linda University & {$[50]$} & Craniopharyngioma & 15 & $93.3 \%$ (median follow-up, 25 months) \\
\hline Rutz & Paul Scherrer Institute & {$[51]$} & Chordoma and chondrosarcoma & 10 & $100 \%$ (median follow-up, 36 months) \\
\hline Yock & Massachusetts General Hospital & {$[52]$} & Orbital rhabdomyosarcoma & 7 & $85.7 \%$ (median follow-up, 6.3 years) \\
\hline Childs & Massachusetts General Hospital & {$[53]$} & Parameningeal rhabdomyosarcoma & 17 & $82 \%$ (median follow-up, 5 years) \\
\hline Cotter & Massachusetts General Hospital & {$[54]$} & Bladder and prostate rhabdomyosarcoma & 7 & $71 \%$ (median follow-up, 27 months) \\
\hline Rombi & Massachusetts General Hospital & {$[55]$} & Ewing sarcoma & 30 & $86 \%$ (3 years) \\
\hline Hattangadi & Massachusetts General Hospital & {$[56]$} & Neuroblastoma & 9 & $100 \%$ (median follow-up, 38 months) \\
\hline
\end{tabular}




\section{Reduction of RT volume by analysis of patterns of failure}

In some tumors, careful patterns of failure analysis have led to a reduction of RT volume. A few decades ago, it was routine to deliver craniospinal irradiation in intracranial ependymoma. Pattern of failure analysis revealed that the primary site was the most common site of failure and $<15 \%$ of patients failed in the neuraxis $[64,65]$. In intracranial germinoma, the whole ventricular field followed by a primary site boost can be treated in M0 disease when RT is used alone [16]. Previously, these patients have also been treated with craniospinal irradiation.

For medulloblastoma, there is now accumulating evidence that tumor bed alone can be treated instead of the entire posterior fossa during the RT boost portion of the treatment. Non-tumor bed posterior fossa failures are uncommon with current imaging and RT technology [13, 14].

\section{Future direction}

While many studies have tried to omit or delay RT, it has become clear that RT will have an important role in the management of many pediatric malignant brain and soft tissue tumors. Genetic testing may help identify subsets of patients who are more likely to develop radiation toxicity. In addition, future molecular and cytogenetic studies may reveal which tumors might be able to be cured without RT. For example, recent molecular subtyping of childhood medulloblastoma has revealed four distinct subtypes [66]. The WNT variety has been found to have the best prognosis and may be amenable to reduction of treatment. More studies are also needed to understand the pathogenesis of late effects of RT. For example, short-term memory loss has recently been linked to hippocampal irradiation. The periventricular and perigranular zones of the hippocampus, important sites for neurogenesis, are thought to be sensitive structures to radiation injury [67]. Several trials are underway using a hippocampal-sparing RT approach in the treatment of brain tumors.

\section{References}

1. Howlader N, Noone AM, Krapcho M et al (eds) (2012) SEER Cancer Statistics Review, 1975-2009 (Vintage 2009 Populations), National Cancer Institute. Bethesda, MD (based on November 2011 SEER data submission, posted to the SEER web site, April 2012). Available from: http://seer.cancer.gov/csr/1975_2009 pops09/.

2. Mertens AC, Liu Q, Neglia JP et al (2008) Cause-specific late mortality among 5-year survivors of childhood cancer: the Childhood Cancer Survivor Study. J Natl Cancer Inst 100:1368-1379

3. Meadows AT, Friedman DL, Neglia JP et al (2009) Second neoplasms in survivors of childhood cancer: findings from the
Childhood Cancer Survivor Study cohort. J Clin Oncol 27:23562362

4. Paulino AC, Constine LS, Rubin P et al (2010) Normal tissue development, homeostasis, senescence, and the sensitivity to radiation injury across the age spectrum. Semin Radiat Oncol 20:1220

5. Duffner PK, Horowitz ME, Krischer JP et al (1993) Postoperative chemotherapy and delayed radiation in children less than three years of age with malignant brain tumors. N Engl J Med 328:1725-1731

6. Grill J, Le Deley MC, Gambarelli D et al (2001) Postoperative chemotherapy without irradiation for ependymoma in children under 5 years of age: a multicenter trial of the French Society of Pediatric Oncology. J Clin Oncol 19:1288-1296

7. Koshy M, Rich S, Merchant TE et al (2011) Post-operative radiation improves survival in children younger than 3 years with intracranial ependymoma. J Neurooncol 105:583-590

8. Merchant TE, Mulhern RK, Krasin MJ et al (2004) Preliminary results from a phase II trial of conformal radiation therapy and evaluation of radiation-related CNS effects for pediatric patients with localized ependymoma. J Clin Oncol 22:3156-3162

9. Rutkowski S, Bode U, Deinlein F et al (2005) Treatment of early childhood medulloblastoma by postoperative chemotherapy alone. N Engl J Med 352:978-986

10. Ferrari A, Casanova M, Bisogno G et al (2003) Rhabdomyosarcoma in infants younger than one year old: a report from the Italian Cooperative Group. Cancer 97:2597-2604

11. Puri DR, Wexler LH, Meyers PA et al (2006) The challenging role of radiation therapy for very young children with rhabdomyosarcoma. Int J Radiat Oncol Biol Phys 65:1177-1184

12. Packer RJ, Goldwein J, Nicholson HS et al (1999) Treatment of children with medulloblastomas with reduced-dose craniospinal radiation therapy and adjuvant chemotherapy: a Children's Cancer Group study. J Clin Oncol 17:2127-2136

13. Gajjar A, Chintagumpala M, Ashley D et al (2006) Risk-adapted craniospinal radiotherapy followed by high-dose chemotherapy and stem-cell rescue in children with newly diagnosed medulloblastoma (St Jude Medulloblastoma-96): long-term results from a prospective, multicentre trial. Lancet Oncol 7:813-820

14. Paulino AC, Mazloom A, Teh BS et al (2011) Local control after craniospinal irradiation, intensity-modulated radiotherapy boost, and chemotherapy in childhood medulloblastoma. Cancer 117:635-641

15. Mulhern RK, Palmer SL, Merchant TE et al (2005) Neurocognitive consequences of risk-adapted therapy for childhood medulloblastoma. J Clin Oncol 23:5511-5519

16. Haas-Kogan DA, Missett BT, Wara WM et al (2003) Radiation therapy for intracranial germ cell tumors. Int J Radiat Oncol Biol Phys 56:511-518

17. Alapetite C, Brisse H, Patte C et al (2010) Pattern of relapse and outcome of non-metastatic germinoma patients treated with chemotherapy and limited field radiation: the SFOP experience. Neurooncology 12:1318-1325

18. Thomas PR, Tefft M, Compaan PJ et al (1991) Results of two radiation therapy randomizations in the third National Wilms' Tumor Study. Cancer 68:1703-1707

19. Paulino AC, Wen BC, Brown CK et al (2000) Late effects in children treated with radiation therapy for Wilms' tumor. Int J Radiat Oncol Biol Phys 46:1239-1246

20. Probert JC, Parker BR (1975) The effects of radiation therapy on bone growth. Radiology 114:155-162

21. Donaldson SS (1981) Hodgkin's disease: treatment with low dose radiation and chemotherapy. Front Radiat Ther Oncol 16:122-133

22. Hodgson DC, Hudson MM, Constine LS (2007) Pediatric Hodgkin lymphoma: maximizing efficacy and minimizing toxicity. Semin Radiat Oncol 17:230-242 
23. De Bruin ML, Sparidans J, van't Veer MB et al (2009) Breast cancer risk in female survivors of Hodgkin's lymphoma: lower risk after smaller radiation volumes. J Clin Oncol 27:4239-4246

24. O'Brien MM, Donaldson SS, Balise RR et al (2010) Second malignant neoplasms in survivors of pediatric Hodgkin's lymphoma treated with low-dose radiation and chemotherapy. J Clin Oncol 28:1232-1239

25. Merchant TE, Nguyen L, Nguyen D et al (2004) Differential attenuation of clavicle growth after asymmetric mantle radiotherapy. Int J Radiat Oncol Biol Phys 59:556-561

26. Bolek TW, Marcus RB Jr, Mendenhall NP et al (1996) Local control and functional results after twice-daily radiotherapy for Ewing's sarcoma of the extremities. Int J Radiat Oncol Biol Phys 35:687-692

27. Chin D, Sklar C, Donahue B et al (1997) Thyroid dysfunction as a late effect in survivors of pediatric medulloblastoma/ primitive neuroectodermal tumors: a comparison of hyperfractionated versus conventional radiotherapy. Cancer 80:798-804

28. Donaldson SS, Meza J, Breneman JC et al (2001) Results from the IRS-IV randomized trial of hyperfractionated radiotherapy in children with rhabdomyosarcoma-a report from the IRSG. Int J Radiat Oncol Biol Phys 51:718-728

29. Mandell LR, Kadota R, Freeman C et al (1999) There is no role for hyperfractionated radiotherapy in the management of children with newly diagnosed diffuse intrinsic brainstem tumors: results of a Pediatric Oncology Group phase III trial comparing conventional vs. hyperfractionated radiotherapy. Int J Radiat Oncol Biol Phys 43:959-964

30. Dunst J, Jurgens H, Sauer R et al (1995) Radiation therapy in Ewing's sarcoma: an update of the CESS 86 trial. Int J Radiat Oncol Biol Phys 32:919-930

31. Lannering B, Rutkowski S, Doz F et al (2012) Hyperfractionated versus conventional radiotherapy followed by chemotherapy in standard-risk medulloblastoma: results from the randomized multicenter HIT-SIOP PNET 4 trial. J Clin Oncol 30:3187-3193

32. Waber DP, Silverman LB, Catania L et al (2004) Outcomes of a randomized trial of hyperfractionated cranial radiation therapy for treatment of high-risk acute lymphoblastic leukemia: therapeutic efficacy and neurotoxicity. J Clin Oncol 22:2701-2707

33. Michalski JM, Sur RK, Harms WB et al (1995) Three dimensional conformal radiation therapy in pediatric parameningeal rhabdomyosarcoma. Int J Radiat Oncol Biol Phys 33:985-991

34. Paulino AC, Narayana A, Mohideen MN et al (2000) Posterior fossa boost in medulloblastoma: an analysis of dose to surrounding structures using 3-dimensional (conformal) radiotherapy. Int $\mathbf{J}$ Radiat Oncol Biol Phys 46:281-286

35. Polkinghorn WR, Dunkel IJ, Souweidane MM et al (2011) Disease control and ototoxicity using intensity-modulated radiation therapy tumor-bed boost for medulloblastoma. Int $\mathrm{J}$ Radiat Oncol Biol Phys $81: e 15-20$

36. Schroeder TM, Chintagumpala M, Okcu MF et al (2008) Intensitymodulated radiation therapy in childhood ependymoma. Int $\mathrm{J}$ Radiat Oncol Biol Phys 71:987-993

37. Laskar S, Bahl G, Muckaden M et al (2008) Nasopharyngeal carcinoma in children: comparison of conventional and intensitymodulated radiotherapy. Int J Radiat Oncol Biol Phys 72:728-736

38. Wolden SL, Wexler LH, Kraus DH et al (2005) Intensitymodulated radiotherapy for head-and-neck rhabdomyosarcoma. Int J Radiat Oncol Biol Phys 61:1432-1438

39. McDonald MW, Esiashvili N, George BA et al (2008) Intensitymodulated radiotherapy with the use of cone-down boost for pediatric head-and-neck rhabdomyosarcoma. Int J Radiat Oncol Biol Phys 72:884-891

40. Curtis AE, Okcu MF, Chintagumpala M et al (2009) Local control after intensity-modulated radiotherapy for head-and-neck rhabdomyosarcoma. Int J Radiat Oncol Biol Phys 73:173-177
41. Yang JC, Dharmajaran KV, Wexler LH et al (2012) Intensity modulated radiation therapy with dose painting to treat rhabdomyosarcoma. Int J Radiat Oncol Biol Phys 84:e371-e377

42. Lin C, Donaldson SS, Meza JL et al (2012) Effect of radiotherapy techniques (IMRT vs. 3D-CRT) on outcome in patients with intermediate-risk rhabdomyosarcoma enrolled in COG D9803-a report from the Children's Oncology Group. Int J Radiat Oncol Biol Phys 82:1764-1770

43. Pinnix CC, Fontanilla HP, Hayes-Jordan A et al (2012) Whole abdominopelvic intensity-modulated radiation therapy for desmoplastic small round cell tumor after surgery. Int J Radiat Oncol Biol Phys 83:317-326

44. Huang E, Teh BS, Strother DR et al (2002) Intensity-modulated radiation therapy for pediatric medulloblastoma: early report on the reduction of ototoxicity. Int J Radiat Oncol Biol Phys 52:599-605

45. Paulino AC, Lobo M, Teh BS et al (2010) Ototoxicity after intensity-modulated radiation therapy and cisplatin-based chemotherapy in children with medulloblastoma. Int J Radiat Oncol Biol Phys 78:1445-1450

46. Paulino AC, Skwarchuk M (2002) Intensity-modulated radiation therapy in the treatment of children. Med Dosim 27:115-120

47. MacDonald SM, Safai S, Trofimov A et al (2008) Proton radiotherapy for childhood ependymoma: initial clinical outcomes and dose comparisons. Int J Radiat Oncol Biol Phys 71:979-986

48. Amsbaugh MJ, Grosshans DR, McAleer MF et al (2012) Proton therapy for spinal ependymomas: planning, acute toxicities, and preliminary outcomes. Int J Radiat Oncol Biol Phys 83:1419-1424

49. MacDonald SM, Trofimov A, Safai S et al (2011) Proton radiotherapy for pediatric central nervous system germ cell tumors: early clinical outcomes. Int J Radiat Oncol Biol Phys 79:121-129

50. Luu QT, Loredo LN, Archambeau JO et al (2006) Fractionated proton radiation treatment for pediatric craniopharyngioma: preliminary report. Cancer J 12:155-159

51. Rutz HP, Weber DC, Goitein G et al (2008) Postoperative spotscanning proton radiation therapy for chordoma and chondrosarcoma in children and adolescents: initial experience at Paul Scherrer Institute. Int J Radiat Oncol Biol Phys 71:220-225

52. Yock T, Schneider R, Friedmann A et al (2005) Proton radiotherapy for orbital rhabdomyosarcoma: clinical outcome and a dosimetric comparison with photons. Int J Radiat Oncol Biol Phys 63:1161-1168

53. Childs SK, Kozak KR, Friedmann AM et al (2012) Proton radiotherapy for parameningeal rhabdomyosarcoma: clinical outcomes and late effects. Int J Radiat Oncol Biol Phys 82:635-642

54. Cotter SE, Herrup DA, Friedmann AM et al (2011) Proton radiotherapy for pediatric bladder/prostate rhabdomyosarcoma: clinical outcomes and dosimetry compared to intensity-modulated radiation therapy. Int J Radiat Oncol Biol Phys 81:1367-1373

55. Rombi B, DeLaney TF, MacDonald SM et al (2012) Proton radiotherapy for pediatric Ewing's sarcoma: initial clinical outcomes. Int J Radiat Oncol Biol Phys 82:1142-1148

56. Hattangadi JA, Rombi B, Yock TI et al (2012) Proton radiotherapy for high-risk pediatric neuroblastoma: early outcomes and dose comparison. Int J Radiat Oncol Biol Phys 83:1015-1022

57. Kuhlthau KA, Pulsifer MB, Yeap BY et al (2012) Prospective study of health-related quality of life for children with brain tumors treated with proton radiotherapy. J Clin Oncol 30:2079-2086

58. Moeller BJ, Chintagumpala M, Philip JJ et al (2011) Low early ototoxicity rates for pediatric medulloblastoma patients treated with proton radiotherapy. Radiat Oncol 6:58

59. Viswanathan V, Pradhan KR, Eugster EA (2011) Pituitary hormone dysfunction after proton beam radiation therapy in children with brain tumors. Endocr Pract 17:891-896

60. Dorffel W, Wolden SL, Chen L H, Kelly KM et al (2012) Longterm results of CCG 5942: a randomized comparison of chemotherapy with and without radiotherapy for children with Hodgkin 
lymphoma - a report from the Children's Oncology Group. J Clin Oncol 30:3174-3180

61. Dorffel W, Luders H, Ruhl U et al (2003) Preliminary results of the multicenter trial GPOH-HD 95 for the treatment of Hodgkin's disease in children and adolescents: analysis and outlook. Klin Padiatr 215:139-145

62. Balmaceda C, Heller G, Rosenblum M et al (1996) Chemotherapy without irradiation - a novel approach for newly diagnosed CNS germ cell tumors: results of an international cooperative trial. J Clin Oncol 14:2908-2915

63. Oberlin O, Rey A, Anderson J et al (2001) Treatment of orbital rhabdomyosarcoma: survival and late effects of treatment- results of an international workshop. J Clin Oncol 19:197204

64. Carrie C, Mottolese C, Bouffet E et al (1995) Non-metastatic childhood ependymomas. Radiother Oncol 36:101-106

65. Paulino AC, Wen BC (2000) The significance of radiotherapy treatment duration in intracranial ependymoma. Int $\mathrm{J}$ Radiat Oncol Biol Phys 47:585-589

66. Northcott PA, Korshunov A, Witt H et al (2011) Medulloblastoma comprises four distinct molecular variants. J Clin Oncol 29:1408-1414

67. Barani IJ, Benedict SH, Lin PS (2007) Neural stem cells: implications for the conventional radiotherapy of central nervous system malignancies. Int J Radiat Oncol Biol Phys 68:324-333 